\title{
San Cristóbal de Las Casas 1864-1872: RADIOGRAFÍA DE UNA CIUDAD EN CRISIS
}

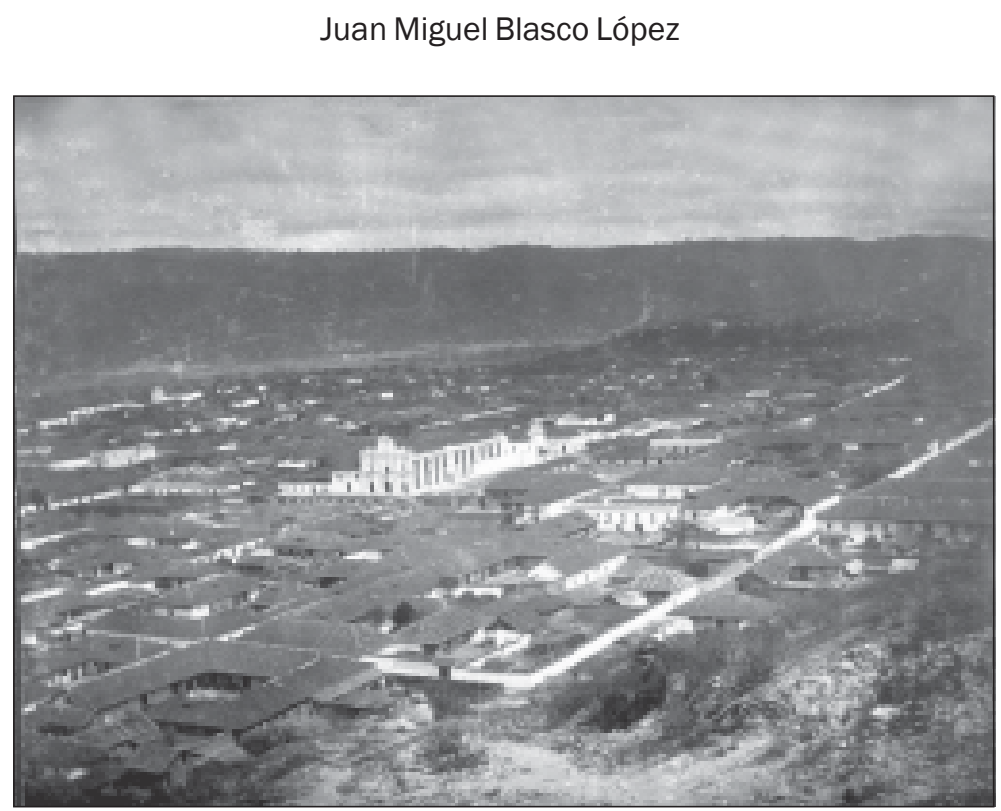

Vista panorámica de San Cristóbal de Las Casas, Teobert Maler, $1877 .{ }^{1}$

\section{Presentación}

A unque en los últimos años se ha profundizado un poco en el estudio del siglo XIX chiapaneco, todavía nos falta mucho por conocer de una época tan trascendente para la conformación del Estado. $^{2}$

Notoria es la ausencia de investigaciones sobre San Cristóbal de Las Casas en el periodo de estudio. Y no se puede atribuir esta laguna a la carencia de fuentes puesto que, a pesar de las lamentables pérdidas experimentadas en los acervos documentales por causa de guerras o desinterés, se conserva importante información sobre la vida política, económica y social de la ciudad en diversos archivos estatales.

En las siguientes páginas quiero ofrecer un breve análisis de la situación de San Cristóbal durante uno de los periodos más dramáticos de su historia, los años comprendidos entre 1864 y 1872. Las informaciones provienen casi en su totalidad del Archivo Municipal de San Cristóbal, que contiene una amplia y variada documentación a partir de 1864. 


\section{De la aventura imperial a la derrota de 1864}

A lo largo de 1863 y en los primeros meses de 1864, Chiapas vivió la definitiva confrontación entre liberales y conservadores, que en líneas generales fue también la lucha de los habitantes de las tierras bajas contra los alteños por el control del aparato de estado y de las poblaciones indias.

Desde la llegada al poder en 1855 de los liberales encabezados por Ángel Albino Corzo, la resistencia de algunos conservadores devino en rebelión armada. El enemigo más persistente fue sin duda Juan Ortega quien aprovechando la protección del presidente guatemalteco Rafael Carrera, irrumpió repetidamente en el estado por la zona fronteriza de Comitán entre 1856 y 1862 . Aunque fuera rechazado en cada ocasión por las tropas del gobierno, nunca pudo ser derrotado pues al sentirse en desventaja tomaba rumbo a la frontera guatemalteca .

En 1863, aprovechando la presencia de las tropas enviadas por Napoleón III para derrocar al régimen liberal e imponer al emperador Maximiliano, la lucha de los conservadores encabezados por Ortega adquirió nuevo impulso.

En el Plan de Yalmuz, abril 1863, Ortega rechazó la Constitución de 1857 y todas las leyes de ella emanadas. También desconoció al gobierno y propuso la restauración de los fueros y privilegios de la iglesia, de la misma manera confirmó a San Cristóbal como capital estatal.

Numerosos sancristobalenses tomaron parte en las actividades políticas y militares del bando conservador, quedando los alteños identificados ante la opinión pública durante los siguientes años como traidores por haberse aliado con la intervención francesa.

La realidad era bastante más compleja debido a que la causa imperial no fue únicamente adoptada por los sancristobalenses. La mayoría de los
Departamentos del Estado también se adhirieron al Plan de Ortega.

Hay que señalar que en San Cristóbal existía también un grupo minoritario de liberales encabezados por Nicolás Ruiz, que se opuso tenazmente a la ocupación de la ciudad por los orteguistas.

Pero la élite sancristobalense se identificó completamente con Ortega, llegando a ocupar un papel destacado en la administración conservadora que trató de institucionalizar el movimiento imperialista en Chiapas.

Tanto las autoridades religiosas como el clero en general apoyaron entusiásticamente a los imperialistas Ya era sintomático el hecho de que un fraile franciscano, Victor Chanona, compartiera con Ortega la dirección de las tropas. En el gobierno provisional que los imperialistas constituyeron en San Cristóbal, Chanona ocupó el cargo de presidente del Consejo de Gobierno, otros miembros del clero asumieron también importantes funciones. ${ }^{3}$

Aquel ambiente de clericalismo exacerbado encontró su momento culmen en la solemne celebración que acompañó al acto de reenclaustramiento de las monjas del convento de la Encarnación el 8 de septiembre.

También el pueblo llano, muy influenciado por el clero, apoyó por unos meses la causa conservadora. Cientos de sancristobalenses formaron parte de las tropas organizadas en octubre para acabar con los últimos bastiones liberales: las ciudades de Chiapa y Tuxtla.

¡Y qué decir de los integrantes del ayuntamiento de 1863, que en lugar de participar en la defensa de su ciudad ante el ataque imperialista del mes de agosto, se desplazaron en su mayoría al cerrito de San Cristóbal, lugar donde estaban apostadas las tropas de Ortega, para ofrecer su adhesión al plan contrarrevolucionario! 
Todo aquel entusiasmo se enfrió súbitamente como consecuencia de la derrota de los imperialistas en las inmediaciones de Chiapa el 21 de octubre. También colaboraron a la pérdida de prestigio de los conservadores las arbitrariedades cometidas por los orteguistas, quienes encarcelaron a numerosos vecinos para cobrarles rescate e impusieron un clima de desconfianza e intransigencia.

Flavio Antonio Paniagua, testigo presencial de aquellos acontecimientos, resume en los siguientes términos la situación de desmoralización que se vivía en San Cristóbal a finales de 1863:

Todos los partidarios de buena fé del imperio se eliminaron de la administración; habían comprendido que no era político, conveniente, ni patriota filiarse en un partido que nada respetaba, que a todo atentaba..

(Paniagua, 1991:50)

En enero de 1864 llegaron a San Cristóbal las tropas constitucionalistas integradas por 1000 guardias nacionales de Chiapas y Oaxaca al mando del coronel Cristóbal Salinas. Tras diez días de combates en los que se fue estrechando el cerco en torno al último bastión de los imperialistas, el convento de Santo Domingo, las tropas de Ortega consiguieron huir aprovechando la oscuridad de la noche.

Una vez restaurado el orden constitucional en Chiapas, las tropas de Oaxaca se retiraron del Estado, quedando como Jefe Político y comandante militar de San Cristóbal el coronel Miguel Utrilla al mando de una fuerza reclutada en la propia ciudad.

La definitiva derrota de las fuerzas de Ortega se produjo en Jonuta en el mes de abril. Se puede decir que en esa ocasión se dio un enfrentamiento entre sancristobalenses: unos formando parte de las tropas de Ortega y otros combatiendo bajo el mando de
Utrilla, también sancristobalense. Allí se puso en evidencia que al menos una parte de los coletos defendía la causa liberal.

\section{Las modalidades del castigo}

\begin{abstract}
...ya nada queda del gobierno Ortega-imperialista con que tanto se os quiso fascinar...

San Cristobaleños: el orden constitucional se halla restablecido en toda su plenitud en vuestro Estado: las autoridades legítimas velan ya por la seguridad de vuestras personas e intereses. Los ciudadanos pacíficos pueden volver tranquilos al seno de sus familias a gozar de todas las garantías que la ley les concede. (Proclama del coronel Salinas, 24 de enero de 1864, en Trens, 1956:44)
\end{abstract}

En unos términos que pasaban del reproche al ofrecimiento de perdón, el coronel Salinas se dirigió a los sancristobalenses después de la huida de las tropas orteguistas. Su llamado a los vecinos de la ciudad para que volvieran a sus casas tardó en surtir efecto. Si bien fueron regresando muchas de las familias que huyeron a lo largo de 1863, un porcentaje de hombres jóvenes y adultos se mantuvo movilizado en uno de los ejércitos combatientes, otros encontraron refugio en los ranchos de la región o en la vecina Guatemala:

Los montes inmediatos, los ranchos, los pueblos, las fincas eran la morada de los hijos de San Cristóbal en enero de 1864. Los partidarios del imperio, por temor, se habían ausentado: los Republicanos, para no quedar expuestos, habían hecho lo mismo. La gente pacífica, engañada con los absurdos y mentiras esparcidas, siguió su ejemplo. Al entrar a San Cristóbal se notaba de momento la ausencia de casi la totalidad de sus habitantes; pocas casas estaban abiertas. (Paniagua, 1990:34) 
$\mathrm{Al}$ margen del periodo crítico padecido en 1863 y 1864 , hay que recordar que tradicionalmente muchos hombres jóvenes emigraban de la ciudad para buscar mejores oportunidades en otras regiones. La crisis económica que se vivió en los siguientes años, las epidemias que se sucedieron en 1864, 1865 y 1867 , así como el reclutamiento por sorteo de las tropas destinadas al ejército nacional, no contribuyeron al regreso de la población masculina.

Por el apoyo demostrado a la causa imperialista, San Cristóbal fue objeto de varias formas de castigo que afectaron a todos los habitantes de la ciudad:

- Argumentando las repetidas sublevaciones que habían tenido lugar en la capital, el gobierno estatal decidió el traslado de los poderes a Tuxtla. Con ello se perdieron recursos que hubieran podido emplearse en la reconstrucción de la ciudad y empleos en la administración pública que pasaron a manos de los ciudadanos de las tierras bajas.

- También se decidió acabar con las influencias que ejercían los sancristobalenses sobre las poblaciones indígenas de Los Altos. Con tal propósito se nombraron en los ayuntamientos secretarios identificados con el gobierno al tiempo que se reducía el protagonismo de la iglesia en las comunidades.

- No se otorgó a San Cristóbal apoyo económico alguno por parte del gobierno estatal para contribuir a la reconstrucción de la ciudad, lo que dificultó mucho los trabajos.

Respecto a los que habían destacado por su participación en el gobierno imperialista se decidió aplicarles multas y quitarles sus derechos ciudadanos. ${ }^{4}$ En esta situación quedaron algunos de los más prominentes integrantes de la élite sancristobalense, como Manuel Esponda, Clemente Francisco Robles, Antero Ballinas, Ciriaco Aguilar, José Antonio Larráinzar, José Gabriel Suasnavar, entre otros. Sin embargo, ninguno de ellos se vio afectado en sus propiedades ni en sus actividades profesionales. Tampoco dejaron de ocupar cargos públicos como Clemente F. Robles - ni de ejercer su influencia política en los ámbitos estatal e incluso nacional. Contaron mucho las amistades, los compadrazgos y el peso que seguían teniendo los antiguos imperialistas como miembros de la oligarquía alteña.

La nueva situación política existente en el Estado abrió las puertas de la administración pública a los liberales, algunos de los cuales destacaron en los negocios y en la política - Miguel Utrilla—. Aún así, el triunfo que para los liberales de Los Altos representó la derrota de los orteguistas se vio opacado por la pobreza y el deterioro que prevalecieron en la región durante los siguientes años, afectando a todos los sectores de la población. Como sancristobalense nadie salió vencedor en 1864 por la crisis en que quedó sumida la ciudad. Ante el abandono exterior, los coletos tuvieron que olvidar muchas de sus diferencias y colaborar en el mantenimiento de su ciudad.

Durante los años siguientes se observó una constante movilidad en los grupos de poder, al ir cambiando alianzas y rivalidades por causas que tenían más que ver con relaciones familiares e intereses económicos que con principios ideológicos. Los conservadores supieron adaptarse a la nueva situación con sentido práctico, sin renunciar por ello a sus principios ni a las acciones que el sistema legal les permitía.

Como una muestra del tipo de enfrentamientos ocurridos en aquellos años, vemos lo acontecido al presidente municipal Casimiro Castañón en 1866.

En 1863, Casimiro Castañón destacó por ser defensor de la causa liberal en el desempeño de su cargo de capitán de la guardia nacional. En consecuencia fue deportado a Tabasco junto con otros liberales por el gobierno orteguista. 
En 1866, mientras ejercía el cargo de presidente municipal, fue acusado de hurto y encarcelado por orden del juzgado de primera instancia. ${ }^{5}$

El fundamento legal del proceso emprendido se basaba en que había recibido cuatro pesos “...de la esposa del finado Don Higinio Trejo, como rédito del capital de 30 pesos destinado a dar de comer a la prisión el día de Jueves Santo".

Casimiro Castañón no había cumplido exactamente el encargo, sino que invirtió esa cantidad, según sus propios términos, en la comida que "...con abundancia y esmero, se dió el 5 de mayo a toda la prisión que ascendía a ochenta y tantos hombres; en la misma fecha no solo se repartió por el que habla comida, sino también mucha fruta y licor".

Más que tratarse de un hurto, el asunto estaba relacionado con los cambios realizados en el calendario festivo, imponiéndose la celebración de una fiesta introducida por los liberales —el 5 de mayo- en sustitución del jueves santo, con lo cual se contrariaba la voluntad del finado Higinio Trejo.

El encarcelamiento de Castañón provocó tal alegría entre sus enemigos que varios de ellos terminaron en la misma cárcel en que se encontraba Castañón:

...El 18 de mayo en la noche entraron en la cárcel Don Manuel Luciano Solórzano y su hermano Don

Ponciano con toda la comitiva que celebraba la entrada de Castañón en la misma cárcel acusado de hurto. (Aubry e Inda, 1989:30)

Manuel y Ponciano Solórzano eran hijos de uno de los más destacados liberales de la ciudad, Ponciano Solórzano y del Barco, quien ocupara en 1848 el cargo de gobernador interino. En menos de tres años, Manuel Solórzano había pasado de ser un liberal perseguido por los imperialistas y desterrado junto a Casimiro Castañón, a convertirse en su enemigo y celebrar junto a los conservadores su enjuiciamiento.

Un año más tarde la suerte de Castañón aún estaba por decidirse. El 12 de julio de 1867 el Jefe Político participó a la Presidencia Municipal que el ex ciudadano Casimiro Castañón había sido denunciado de vago y malentretenido ante la Comisión de Policía.

Una semana después un grupo de munícipes del Ayuntamiento facultó al regidor Solórzano para que exigiera ante el juzgado competente la acción civil y penal al ex presidente municipal Castañón por los 4 pesos recibidos un año antes. ${ }^{8}$

Finalmente el caso se resolvió favorablemente para Casimiro Castañón al quedar exonerado de la acusación de hurto. Como muestra de su rehabilitación ciudadana fue designado el 23 de julio para ocupar el cargo de alcalde segundo.' Eso sí, tuvo que participar en las sesiones del Ayuntamiento junto a varios de sus enemigos y denunciantes, como el propio regidor Solórzano.

Este tipo de denuncias expresaban un afán de venganza que frecuentemente encontró su vía de expresión en los tribunales. También evidenciaba una recomposición de las alianzas entre ciudadanos ya no tan claramente identificados con su filiación ideológica de años anteriores.

La exoneración de Castañón tuvo que ver con la existencia de jueces liberales designados por el gobierno del Estado, que sirvieron de contrapeso al grupo conservador de fuerte implantación a nivel local.

En 1872, cuando se iniciaron las obras de construcción de la casa consistorial, se pidieron 300 pesos que José Antonio Larráinzar conservaba para pagar las misas de la cárcel. En este caso no hubo denuncias ni escándalos por el cambio de destino dado a los fondos. ${ }^{10}$ 


\section{Una ciudad en crisis}

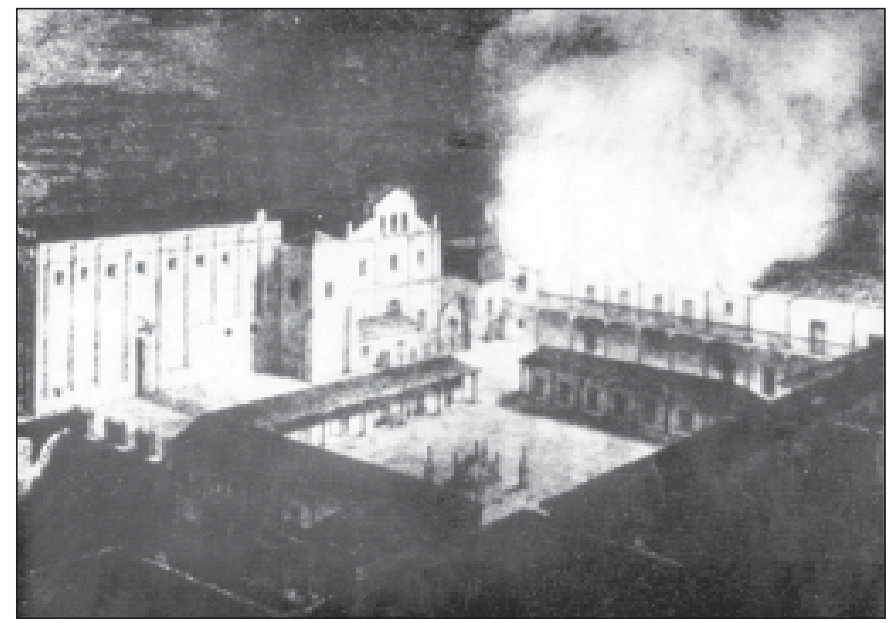

Incendio del Palacio de Gobierno por las tropas Imperialistas en agosto de 1863. Litografía anónima. ${ }^{11}$

A partir de la información contenida en el Archivo Municipal de San Cristóbal se puede obtener una imagen bastante detallada de la crisis en que cayó la ciudad desde 1864, que sólo llegaría a ser superada en los años 70 con el regreso de la capital a Los Altos y el inicio de la recuperación de las actividades económicas en la región.

A finales de enero de 1864, San Cristóbal ofrecía una imagen desoladora. Las calles semidesiertas y decenas de edificios en ruinas daban constancia de los combates mantenidos en agosto de 1863 y enero de 1864. A ello se añadió en septiembre la caída, a consecuencia de las intensas lluvias, del Puente Blanco, principal vía hacia las tierras bajas. Además a lo largo del año se padeció una epidemia de tifus.

Con una economía en retroceso y una situación política incierta, el Ayuntamiento trató de reorganizarse para atender a la crítica situación existente. El reto era casi insuperable.

La mayoría de los integrantes del Ayuntamiento, 1863, quedaron inhabilitados para el desempeño de cargos públicos, ${ }^{12}$ y lo que aún fue más grave, los archivos de la ciudad habían desaparecido tras el incendio del edificio de palacio de gobierno que se produjo en agosto durante la toma de San Cristóbal por las fuerzas orteguistas.

Respecto a los ciudadanos inhabilitados, en repetidas ocasiones el gobierno del Estado obligó al Ayuntamiento a destituir a algunos de sus munícipes.

En 1864 se recibió en el Ayuntamiento el siguiente comunicado del gobierno estatal:

Tiene informes este Gobierno de haber sido nombrado Secretario Municipal de esta ciudad el Sr. Toribio Espinoza: y como la conducta que este señor observó durante el transitorio reinado de los traidores en la misma no lo hacen acreedor a la confianza pública: el Ayuntamiento que Ud. Dignamente preside, se servirá proceder al nombramiento de otra persona que dé mejores garantías de adhesión a la causa y de amor a la independencia y libertad de la patria. ${ }^{13}$ 
En 1868 fueron cesados de sus cargos de alcaldes 1 y 4, José Leonardo Pineda y Juan Nepomucemo Morales, “...por cuanto prestaron servicios a la causa del llamado imperio... el primero como primer magistrado del Superior Tribunal de Justicia y el segundo como Juez de Primera Instancia". ${ }^{14}$

La situación más grave se produjo en 1869, cuando fueron destituidos varios alcaldes y capitulares del Ayuntamiento "...con motivo de no gozar el fuero de ciudadanía por no estar rehabilitados..."15. Uno de los nombramientos anulados fue el de José Gabriel Suasnavar, quien ocupara el puesto de Magistrado del Superior Tribunal de Justicia en el gobierno imperialista de 1863. También abandonaron sus puestos Ramón Franco, Porfirio Trejo, Manuel Molina y Tomás Ochoa. El Ayuntamiento tardó varios meses en encontrar sustitutos para los cargos destituidos que cumplieran con los requisitos legales.

A partir de 1870, dejaron de producirse estas situaciones al aceptarse que los colaboradores del imperio que hubieran sido rehabilitados pudieran ocupar puestos en la administración municipal. El decreto publicado por el Congreso del Estado en septiembre del mismo año delimitó claramente los cargos que no podían ser ocupados por los antiguos imperialistas:

Cualquier persona que haya servido a la intervención extranjera o el llamado imperio, no podrá ser Gobernador del Estado, Diputado al Congreso del mismo, Magistrado del Tribunal Superior de Justicia, Secretario de Despacho de Gobierno, ni Tesorero General, aunque esté rehabilitado para el ejercicio de sus derechos de ciudadano. ${ }^{16}$

En aquel clima de inestabilidad y desconfianza los gobiernos municipales tuvieron que enfrentar el reto de reconstruir la ciudad en medio de una escasez asfixiante. La quema de los archivos privó a los tesoreros de las informaciones indispensables para su trabajo:

En esta oficina se carece del plan de arbitrios y otros documentos que deben constituir el archivo, y por la falta de ellos el empleado que la desempeña no puede expeditar las recaudaciones que le corresponde hacer... ${ }^{17}$

Las fuerzas orteguistas dejaron las arcas de la ciudad vacías y una gran cantidad de empréstitos forzosos que nunca serían recuperados. A ello hay que añadir que los liberales aplicaron el mismo recurso para sufragar los gastos generados por las campañas militares. Al respecto señala Francisco Villafuerte en su diario personal:

Miércoles 24 de octubre de 1866 me puso preso en la Iglesia de San Nicolás el Gobernador D. Pantaleón Domínguez porque me exigía mil pesos, y quedó en doscientos poniéndome en libertad el día siguiente. (Aubry e Inda, 1989:31)

Sin libros ni documentos, con el último tesorero municipal inhabilitado y sin apenas ingresos, el cargo de tesorero municipal se convirtió en uno de los puestos más detestados por algunos años. Sólo en 1864 hubo tres tesoreros que tuvieron que dejar el cargo por similares motivos, uno de ellos señalaba 2 “...no me es posible ya seguir atendiendo a las necesidades que concurren en el fondo municipal por mi notoria escasez..." ${ }^{18}$ Otro de los tesoreros apuntaba "...que hizo un empréstito de 209 pesos 49.5 centavos y que sigue sin fondos... y que de día en día aumentan los males..." 19

El comercio regional se redujo drásticamente por la crisis económica del Estado y por las amenazas de nuevos estallidos revolucionarios. La crisis se 
evidenció al realizarse los remates de las garitas y las carnicerías en 1865 y quedar desiertos en dos ocasiones. En consecuencia el Ayuntamiento acordó:

...que siendo ya el tercer pregón para el remate de garitas
y carnicerías que previene la ley, y no apareciendo hasta
esta fecha postor alguno a ellas, se les hace la baja de
una tercera parte, quedando por base para el de
carnicerías la suma de $\$ 46.66$, para el de la Garita de
San Diego la cantidad de $\$ 40.00$ y para el de la Garita
de Guadalupe, la suma de $\$ 26.66$, por las que se
rematarán en la próxima sesión en subasta pública. ${ }^{20}$

Los rematantes consiguieron que se aceptara incluir la siguiente cláusula en los contratos:

...con la circunstancia de que en un caso fortuito o de asedio de esta ciudad que justifique suficientemente se le considerará en la cuota correspondiente al tiempo que permanezca... ${ }^{21}$

Los ingresos que el Ayuntamiento obtenía por los remates de los derechos cobrados en las garitas de Guadalupe, San Diego y la Merced debido a las mercancías introducidas a la ciudad, constituían un componente básico de los activos de la Tesorería Municipal, por lo que su reducción a partir de 1864 trajo importantes consecuencias. ${ }^{22}$

En aquellas circunstancias, que la escuela pública estuviera totalmente desatendida, que en la cárcel se denunciara repetidamente que los presos pasaban hambre o que se dejaran de pagar los salarios a los funcionarios dependientes del Ayuntamiento era bastante previsible.

Otro problema que tuvo que enfrentar el Ayuntamiento fue el de la inseguridad. El contingente de la guardia nacional, instalado en la ciudad, no colaboró en las tareas de mantenimiento del orden público, que permanecieron bajo la responsabilidad del Ayuntamiento.

Uno de los lugares donde mejor se podía comprobar la falta de seguridad era paradójicamente la cárcel. En marzo de 1864 se dirigió el Jefe Político al Ayuntamiento para señalarle:

...anoche se han fugado 13 presos de homicidio y como este acontecimiento me hace presumir que permaneciendo la prisión sin llaves, sin guardias e insegura continuarán fugándose los otros reos... ${ }^{23}$.

Si la seguridad en la cárcel era precaria, aún más difícil era mantener la vigilancia de los presos cuando salían a hacer trabajos públicos. En más de una ocasión los vigilantes fueron encerrados en la misma cárcel que custodiaban por haber descuidado las tareas de vigilancia e incluso por haber colaborado en las fugas de algunos presos.

Como consecuencia de los acontecimientos de 1863, el gobierno estatal decidió quitar al Ayuntamiento las armas de fuego con que contaba para hacer las guardias nocturnas. El problema es que sólo se encontraba la autoridad sin armas. En enero de 1868. se indicaba que "...en la actualidad todos los vecinos transitan en la población armados. ${ }^{24}$ Frente a esta situación, en mayo del mismo año se ....acordó hacer un bastón borlado con el fin de que los jefes de ronda puedan representar a su vez la autoridad que ejercen". ${ }^{25}$

Unos meses más tarde el Jefe Político autorizó poner a disposición del cuerpo de ronda dos carabinas y así ayudar a imponer respeto a la autoridad, "...para hacer cerrar las cantinas a la hora de queda, y registrar a todos los que de noche andan con toda clase de armas sin tener licencia para portarlas...", cosa que acostumbraban "...la mayor parte de las personas que disfrutan el título de decentes y principales en la sociedad". ${ }^{26}$ 


\section{Acoso a la población indígena en San Cristóbal}

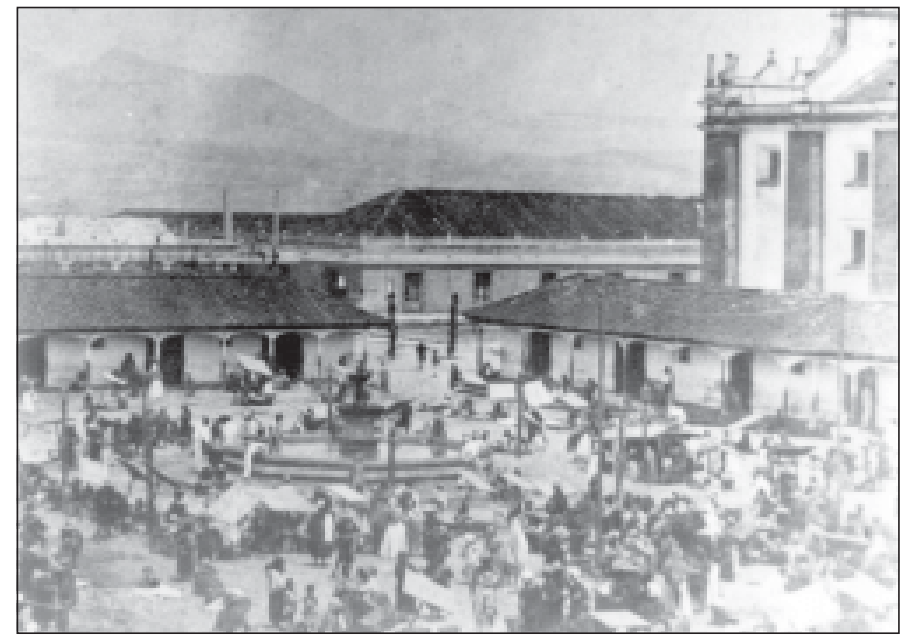

Mercado de San Cristóbal en la Plaza Mayor, anónimo, circa $1890 .^{27}$

Toda la difícil situación aquí descrita tuvo repercusiones en los indígenas de los pueblos y parajes cercanos a la antigua capital. Si bien San Cristóbal perdió a partir de 1864 todo protagonismo en los municipios indígenas de Los Altos, siguió conservando cierto control sobre las poblaciones que abastecían de productos agrícolas al mercado de la ciudad.

En la documentación del Ayuntamiento aparecen numerosas constancias de los abusos a que fueron sometidos los indígenas a partir de 1864.

Ante la imposibilidad de disponer de recursos para el pago de salarios a los obreros ocupados en las actividades de desescombro y reconstrucción de los edificios de la ciudad dañados por los combates y del Puente Blanco, se procedió a detener a numerosos indígenas en las vías de acceso a San Cristóbal para ocuparlos en tareas diversas, tales como la limpieza y acarreo de agua al cuartel o las obras de reconstrucción emprendidas en la ciudad.

Para dar una apariencia legal a estos trabajos forzosos y gratuitos, el Jefe Político realizó la siguiente propuesta al Ayuntamiento:
Estando emprendida la obra del Puente Blanco y deseando la Jefatura de mi cargo proveer los brazos necesarios a los maestros encargados de ella... be creído del caso ocurrir por la presente y por su conducto a dicho cuerpo para que dicte sus órdenes a fin de que los Ciudadanos Regidores salgan a las entradas de esta Ciudad a hacer que los Jefes de Cuartel y demás individuos del ramo de policía cumplan con las órdenes... para la aprensión y conducción a la cárcel de todos los ebrios que constantemente se encuentren y se consignen al trabajo. ${ }^{28}$

Es importante resaltar que el Jefe Político se refiere a las “...entradas de esta Ciudad..." como territorio para detener a los ebrios, con lo cual quedaban excluidos de tal amenaza los vecinos del centro que contaban con sus propias y más o menos respetables cantinas. Se trataba de detener a los indígenas que salían de la ciudad ebrios después de haber dejado parte de los ingresos obtenidos por la venta de sus productos en alguno de los más de doscientos expendios de aguardiente existentes en la periferia de San Cristóbal. 
A esta venta legal de aguardiente se añadía la que de modo clandestino se realizaba en los pueblos habitados por indígenas.

Ya en 1804 informaba el Gobernador Intendente que "...ha destinado dos alguaciles que salen al camino a cuidar de los indios que vuelven ebrios de esa Ciudad..." (Inda, 1986:15).

En 1848, el vicario interino de Chamula describía el comercio de aguardiente que se realizaba en la capital:

...pero lo que corrompe... lo que destruye sus cortos bienes y los aniquila... es la abundancia suma de aguardiente y la libertad con que se vende en esa Ciudad que abastece a los pobres pueblos en los ranchitos, en los caminos, en las galeritas formadas a un lado de los caminos... que da horror al ver vender el agua ardiente, y dejar al pueblo en un estado escandaloso (ibid, 105).

La situación no había cambiado en 1856 si atendemos a la afirmación del cura de Chamula que “...muy pocos son los que entran [a San Cristóbal] sin salir ebrios" (ibid, 61).

La destilación y venta de aguardiente en la ciudad era una actividad tradicional, consentida y hasta tutelada por las autoridades locales. Con la propuesta del Jefe Político pasó a convertirse además en fuente de persecuciones y encarcelamientos. El fundamento legal para emplear en las obras públicas a quienes fueran encontrados en estado de ebriedad se encontraba en el artículo núm. 65 de la ley reglamentaria de la administración política de los departamentos y municipios, que exponía:

A los que por embriaguez o cualquier otro motivo turben la tranquilidad pública o los desobedezcan, podrán los presidentes municipales imponer hasta cincuenta pesos de multa, o quince días de obras públicas o doble tiempo de arresto. ${ }^{29}$
Dicha ley estaba en vigor desde 1862.

Las obras de reconstrucción del Puente Blancollamado oficialmente desde entonces Puente Utrillaocuparon por más de un año a gran número de presos que habían cometido el delito de consumir el aguardiente que libremente se les vendía en la ciudad. La celebración por la finalización de las obras alcanzó a los indígenas que participaron gratuitamente:

A moción del Jefe Político el Ayuntamiento resolvió que el obsequio preparado para los indígenas de los pueblos del Departamento se reduzca puramente a copas de aguardiente y pan atendiendo a la escasez de fondos. ${ }^{30}$

No deja de ser curioso que el mismo Jefe Político que en diciembre de 1864 ordenara la detención de ebrios para ser utilizados en las obras del puente, ahora propusiera el reparto de aguardiente entre los indígenas para agradecerles su colaboración.

En los años 1866 y 1867 se continuaron utilizando a los indígenas en numerosas actividades forzosas y gratuitas, lo que condujo a la disminución del número de ellos que acudían a la ciudad para abastecerla de productos de primera necesidad o para ofrecer otro tipo de servicios. Los abusos cometidos fueron generando un creciente aislamiento de San Cristóbal que necesitaba de ese comercio regional para su propia supervivencia.

El 20 de febrero de 1866 el Ayuntamiento se dirigió al Jefe Político para exponer su preocupación por la escasez de indígenas que ingresaban a la ciudad:

...que notándose la carestía de toda clase de abasto en la plaza pública de esta ciudad, se invita al Jefe Político a fin de que dicte sus órdenes, prohibiendo los abusos que comete la tropa con los indígenas abastecedores, cogiéndolos a fuerza para dedicarlos a faenas a que por ningún motivo están obligados, así como para que 
éstos queden exonerados del trabajo que les exigen en el puente, supuesto que por tales motivos temen concurrir a la plaza con sus víveres. ${ }^{31}$

El Jefe Político contestó al día siguiente sin referirse a la mano de obra utilizada en el puente, aunque sí a las molestias provocadas por la tropa:

...que para lo único que los guardias nacionales tocan algunos indígenas, es para el acarreo de agua que tanto se necesita en el Cuartel de mi mando, siendo así que con este pequeño servicio no son perjudicados absolutamente. Mas si otras personas los han maltratado, por lo cual no concurren a la plaza pública de esta ciudad con sus respectivos víveres, lo ignora esta Jefatura Política y Comandancia Militar. ${ }^{32}$

En el mes de enero de 1867, el Ayuntamiento insistió en señalar los abusos de la tropa:

Habiendo manifestado la Comisión de Abasto que los soldados cometen abusos en la compra de víveres que verifican en la plaza pública, así como el de coger indígenas para el servicio del cuartel sin la justa retribución. ${ }^{33}$

Dos años después seguía dándose la misma situación. En marzo de 1869 el Ayuntamiento propuso al Jefe Político que los quehaceres necesarios del cuartel los realizara un preso “....y de este modo se evitan las vejaciones que constantemente reciben los indígenas que concurren a la plaza de esta ciudad". ${ }^{34}$

Un tema que se planteó en 1866, como tantas otras veces antes y después, fue el de los reiterados abusos cometidos igualmente por las atajadoras — también llamadas regatonas-. El 16 de noviembre el Ayuntamiento comunicó a la comisión de abasto que “...ordene a los Jefes de Cuartel vigilen por medio de sus comisionados, los abusos que cometen los regatones y regatonas que abarcan en los caminos los víveres, a efecto de cortarlos". 35
Para acabar de completar el panorama de imposiciones y abusos, el Ayuntamiento acordó en julio de 1867 “...que todos los indígenas que ingresen a esta población dejen en las respectivas entradas de los caminos una piedra cada uno... Cuatro días después se amplió la orden ...aún hasta con los mozos y leñateros". 36

Como se puede comprobar en los documentos citados, la situación en San Cristóbal no era favorable para que los indígenas llegaran a vender sus productos. Aparte de tener que llegar a la ciudad cargando una piedra — además de sus mercancías—, había muchas posibilidades de que fueran interceptados a la entrada por los soldados o las regatonas. A la salida les esperaban las expendedoras de aguardiente dispuestas a quedarse con una parte de lo obtenido en las transacciones comerciales. Y si tenían la mala suerte de ser encontrados en estado de ebriedad, los Jefes de Cuartel los enviaban a la cárcel para purgar su falta con varios días de trabajos públicos.

\section{8-1869: crece el temor y finalmente estalla la violencia}

A partir de los primeros meses de 1868 dejaron de producirse denuncias por malos tratos o abusos cometidos hacia la población indígena. La causa fue que empezaron a llegar noticias sobre el rápido aumento del número de indígenas que acudían al paraje de Tzajalhemel para participar en las ceremonias realizadas en una ermita levantada por ellos mismos. Los cultos estaban presididos por Agustina Gómez Checheb y Pedro Díaz Cuzcat. ${ }^{37}$

Rumores de una inminente sublevación empezaron a circular entre las poblaciones ladinas de Los Altos, coincidiendo con un cambio de actitud por parte de los habitantes de San Cristóbal, que dejaron de buscar entre sus propios abusos las causas de la ausencia indígena. Ahora habían encontrado una respuesta que 
los exoneraba de toda culpa: los indígenas dejaron de ser considerados como víctimas y pasaron a convertirse en una amenaza a los ojos de la mayoría de los sancristobalenses.

A lo largo de 1868 la presencia de indígenas en San Cristóbal se fue reduciendo, al tiempo que crecían las actividades comerciales en Tzajalhemel. Con ello se agudizó el desabastecimiento de la ciudad y la sensación de indefensión de sus vecinos.

El hecho de que los indígenas se reunieran para adorar a sus dioses también era visto como una potencial amenaza por el gobierno estatal, que el primero de mayo se dirigió al Jefe Político en los siguientes términos:

En virtud de la alarma que oficialmente sabe este Gobierno haber causado en esa ciudad la reunión de indios que con carácter sospechoso tiene lugar en el pueblo de San Miguel Mitontic a pretexto de la adoración de un santo, este Gobierno está dictando sus providencias para enviar prontamente fuerzas que den seguridad a esta Ciudad y que apoyen las medidas que haya de tomar el Gobierno para evitar de raíz el mal, que pudiera amenazar a la Sociedad... ${ }^{38}$

Dos días más tarde el Jefe Político de Los Altos encabezó una expedición militar a Tzajalhemel, procediendo a la detención de Agustina Gómez Checheb y confiscando algunas imágenes. Unos días después el gobierno ordenó la liberación de la detenida en cumplimiento de la ley de libertad de cultos, decisión que fue criticada por los sancristobalenses.

Todos estos acontecimientos no generaron actos de violencia por parte de los indígenas. Sin embargo, en las versiones que de los hechos aparecen en la documentación municipal se presenta a los indígenas como causantes de un tumulto y no como víctimas de la acción militar emprendida por el Jefe Político.

En el libro de actas de las sesiones del Ayuntamiento se habla de "...la alarma que causaron a esta población los indígenas...". Días después aparece otra referencia al "...tumulto formado por indígenas chamulas...."39

Pese a la ausencia de actos de violencia por parte de los seguidores del culto autóctono de Tzajalhemel hasta junio de 1869, el fantasma de la guerra de castas siguió creciendo en la población de la ciudad.

En diciembre de 1868, el Jefe Político decidió el encarcelamiento de Pedro Díaz Cuzcat, Agustina Gómez Checheb y varios de sus seguidores, quienes quedaron presos en las cárceles de San Cristóbal.

El año 1869 comenzó con un decaimiento del número de asistentes a la ermita de Tzajalhemel y cierta recuperación del comercio regional en la antigua capital. En mayo se observó de nuevo una disminución de los comerciantes indígenas en la ciudad debido al inicio del cobro del impuesto de capitación decretado por el gobierno estatal (Rus, 1995:164-165).

La guerra de castas que estaba ya en la mente de muchos desde 1868 finalmente adquirió algunos visos de realidad tras los asesinatos cometidos por los indígenas a partir del 12 de junio de ese año.

La noticia de los asesinatos del cura y el maestro de Chamula llegó a la ciudad en pocas horas, provocando la celebración de una sesión extraordinaria del Ayuntamiento en la que se informó que "...se sabe la muerte del cura y maestro de aquel pueblo [Chamula], aunque no oficial ni a ciencia cierta, pero que este solo hecho hace patente la hostilidad que un gran número de aquel pueblo ya expresado ejerce hacia esta ciudad".40

Para proteger a los ciudadanos de cualquier posible ataque, se repartió una circular entre los Jefes de Cuartel que decía:

En el acto que ustedes reciban la presente, citarán a todos los individuos de sus respectivas secciones para que sin pérdida de momento se reúnan en las plazuelas de sus mismas secciones, con las armas que cada cual tenga para estar a la defensiva de cualquier ataque que el pueblo de Chamula intente dar contra 
esta población, pues se tienen partes de que se prepara dicho pueblo con este propósito.$^{41}$

Durante los siguientes días se produjeron varias decenas de asesinatos de ladinos en diversas fincas de San Miguel y Santa Marta. También fueron asesinados el maestro de Chalchihuitán, su familia, y el párroco, así como cinco comerciantes del barrio de Cuxtitali.

El 17 de junio, miles de indígenas se concentraron a las orillas de San Cristóbal encabezados por Ignacio Fernández de Galindo ${ }^{42}$ con el propósito de exigir la liberación de Díaz Cuzcat, Gómez Checheb y los otros indígenas presos. Como consecuencia de las conversaciones entabladas con las autoridades locales se acordó que los presos indígenas fueran liberados, quedando como rehenes Fernández de Galindo y sus dos acompañantes.

Tres días más tarde se dio un enfrentamiento entre indígenas y ladinos que produjo numerosas bajas por ambos bandos. Esta acción sería recordada años después por los sancristobalenses como la "Acción del Callejón”, y considerada como la ocasión en que más cerca estuvo la ciudad de ser tomada por los indígenas.

Todo empezó con el arribo al valle de Jovel de miles de indígenas encabezados por Pedro Díaz Cuzcat e Ignacio Collazo Panchín reclamando la libertad de Fernández de Galindo. Para fortuna de los sancristobalenses llegaron en esos momentos trescientos soldados encabezados por el gobernador Pantaleón Domínguez que ayudaron a contener y finalmente hacer retroceder a los indígenas. Fernández de Galindo y su ayudante Benigno Trejo fueron fusilados pocos días después tras un breve juicio militar.

Durante las siguientes semanas se produjeron enfrentamientos en Chamula, Yolonchén y San Andrés con un saldo de centenares de indígenas muertos. Para noviembre de 1869 se había concluido la "pacificación" en Los Altos Centrales, aunque todavía hubo enfrentamientos menores en el Departamento de Simojovel unos meses más tarde (Rus, 1995:171).

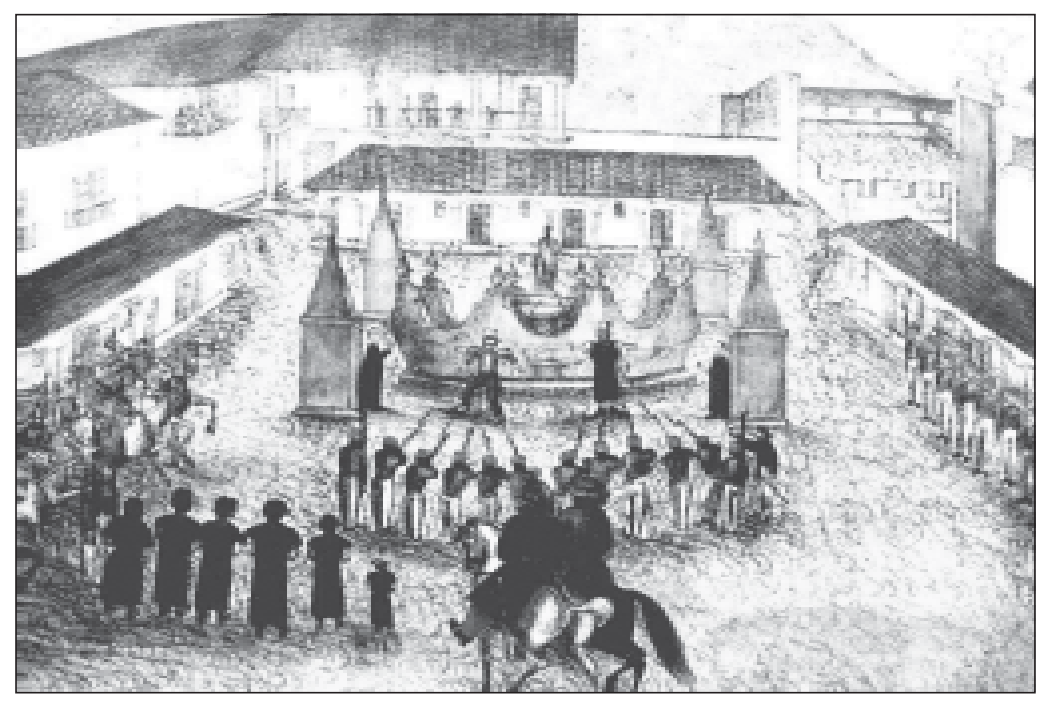

Fusilamiento de Ignacio Fernández de Galindo y Benigno Trejo, Plaza Mayor de San Cristóbal, junio de 1869, litografía coloreada, Pedro Martínez. ${ }^{43}$ 


\section{E1 regreso de la capital a Los Altos}

Los acontecimientos de 1869 supusieron un cambio de actitud del gobierno respecto a la situación en Los Altos. El olvido deliberado que practicaron las autoridades estatales respecto a la suerte de los alteños desde 1864, dio paso a una mayor comprensión de las razones que les impulsaban a someter todo intento de separatismo indígena.

El gobernador Pantaleón Domínguez afirmó en su proclama del 16 de junio:

Hoy no se trata de este o aquel partido, la defensa de tal o cual principio político; hoy solo se trata de la salvación de los pueblos de los feroces instintos del salvajismo. (Manguen y Montesinos, 1981:31)

Este cambio de actitud del gobierno estatal partía de la necesidad de unir a toda la población ladina con un objetivo compartido: recuperar el control de las poblaciones indígenas con el fin de hacer posible la utilización de sus tierras y habitantes en el proyecto de desarrollo emprendido.

La represión desencadenada en 1869 y 1870 sirvió para escarmentar a los indígenas que buscaban emanciparse de los controles e imposiciones de los ladinos, tanto en la esfera religiosa como en sus actividades comerciales. En todas las comunidades que se vieron envueltas en el levantamiento - Chamula, San Andrés, Mitontic, Chenalhó, Santa Marta, Simojovel... - se produjo un reemplazo de sus autoridades, imponiendo a quienes habían colaborado en la represión.

Las condiciones de sometimiento en que quedaron las comunidades indígenas de Los Altos hicieron posible la restauración del poder de la capital en los flujos comerciales de la región, una vez desaparecidas las redes comerciales alternativas surgidas en torno a Tzajalhemel.
En los siguientes años se incrementó la presencia ladina en los municipios indígenas de Los Altos; el aumento en el número de fincas y ranchos se vio acompañado por el asentamiento de ladinos en las cabeceras municipales que en pocos años se hicieron con el control del comercio local, la producción y venta de aguardiente, y el enganche de trabajadores para las labores agrícolas de otras regiones del estado.

Respecto al trato dado a los indígenas en San Cristóbal, la documentación municipal volvió a comentar el tema de las actividades de las regatonas en 1870. Un vecino de la ciudad se dirigió a la comisión permanente de abasto para denunciar que:

El C. Agustín Basques, actual Juez de Plaza, comete abundantes excesos en el ejercicio de sus funciones, prefiriendo en el abasto a las regatonas, mas bien que al pueblo... ${ }^{44}$

Las regatonas no sólo seguían ejerciendo impunemente su actividad, sino que contaban con la complicidad de algunas autoridades locales. Esta situación no había cambiado en los años recientes ni cambiaría en los decenios por venir.

Desde el punto de vista político los acontecimientos de 1869 y 1870 propiciaron el reagrupamiento de los conservadores alteños en torno al objetivo de recuperar la presencia perdida en el Estado. En su actuación contaron con un medio de difusión propio, el periódico La Brújula. Desde sus páginas los editores, autoproclamados portavoces de la sociedad local, expusieron ampliamente su interpretación de los acontecimientos de 1869 como una expresión de "...la lucha asoladora del salvaje contra el hombre civilizado, del progreso contra el retroceso...". ${ }^{45}$

Los que se atrevieron a disentir de estas versiones fueron considerados traidores a la causa de la civilización. Al liberal Octaviano Robles llegaron a 
tildarlo de hermafrodita por no quererse definir entre los dos bandos enfrentados al no sentirse identificado con ninguno de ellos.

Pese a las disputas que enfrentaban a los sancristobalenses, todos coincidían en la urgencia del retorno de los poderes estatales. Unos confiaban en la mayor seguridad que tendría la ciudad al aumentar la presencia de la guardia nacional, otros esperaban que el regreso de los poderes traería una mayor actividad comercial a Los Altos y algunos más esperaban ocupar puestos en la administración pública.

En noviembre de 1867 se decretó en la capital federal que para favorecer a la pacificación del país las capitales de estado desplazadas por la guerra volvieran a sus antiguas sedes.

El gobernador Domínguez pospuso por unos años el regreso de los poderes a San Cristóbal argumentando la falta de seguridad existente en Los Altos.

$\mathrm{Al}$ regresar en 1872 la capital a su antigua sede, la ciudad seguía sumida en una profunda crisis. La situación económica no había mejorado respecto a la de 1865. Si bien el comercio regional se fue recuperando lentamente a partir de 1870 , siguieron circulando rumores de nuevos levantamientos que atemorizaban a los comerciantes.

La población masculina adulta seguía siendo escasa en la ciudad por el temor de muchos jóvenes a ser reclutados para el ejército.

En 1871 se agudizó el problema por “...haber colocado sobre las armas una porción de hombres de toda clase y aprehendidos con sorpresa... de modo que los demás hombres... han ido emigrando y desavecindando de esta población. Han quedado estos lugares, como es público, asolados..." .46

La escasez de ciudadanos que pudieran asumir los cargos municipales hizo más difícil la actuación del Ayuntamiento. Frecuentementelas personas acomodadas que eran designadas para ocupar cargos en la corporación municipal eludían su responsabilidad presentando certificados médicos que atestiguaban padecimientos crónicos inexistentes. Esto provocaba que

...escaseándose así las personas que deben servir los cargos públicos, vienen éstos a recaer en las que pertenecen a las clases menesterosas que son las que menos pueden conseguir, pagando, una falsa certificación... ${ }^{47}$

Según el Jefe Político, lo que demostraba el uso abusivo de las certificaciones era que, a personas excluidas del Ayuntamiento por enfermedad “...se les ve ejercitarse física y mentalmente en los trabajos y ocupaciones de su industria particular...". ${ }^{48}$

Respecto a las finanzas municipales la situación seguía siendo crítica. La Tesorería Municipal dejó de pagar durante varios meses los salarios de los empleados de los juzgados municipales y de los maestros. En mayo destituyeron al Tesorero por inepto pero la situación no mejoró después. El desánimo pareció apoderarse de la corporación municipal, dejando de celebrarse algunas sesiones ordinarias del Ayuntamiento.

Sobre el estado en que se encontraba la escuela pública, señaló el Jefe Político :

El día de hoy pasé personalmente a visitar la escuela pública de primeras letras de esta ciudad y por cierto me fue muy sensible y extraño ver el estado de abandono en que se encuentra este establecimiento... ${ }^{49}$

En las cárceles de la ciudad la situación llegó a ser tan caótica que en los primeros cinco meses del año se sucedieron cinco alcaides. ${ }^{50}$ Unos fueron destituidos por cobrar carcelajes ${ }^{51}$ o por colaborar en la fuga de algunos presos, otro renunció por no poder soportar “... las vejaciones que allá se sufren... que han afectado mi salud y mi reposo". ${ }^{52}$

También los puentes, calzadas y caminos de la demarcación necesitaban ser reparados urgentemente, 
y la propia ciudad precisaba obras de saneamiento e higiene. Según una comunicación de la Jefatura Política:

...esta población... el estado que guarda es enteramente deplorable... dejando que las calles se inunden en la más asquerosa corrupción, se cubran de yerbas y se desequen en ellas hasta los animales que mueren; $y$ esto aún en las más principales..$^{53}$

Éste era el triste panorama que ofrecía San Cristóbal, en 1872, año en que regresaron los poderes estatales.

\section{Notas}

${ }^{1}$ Instituto Iberoamericano. Fundación Patrimonio Cultural Prusiano, Berlín, Alemania, Archivo histórico de la ciudad de San Cristóbal

2 Agradezco al Maestro Justus Fenner por su valiosa colaboración en la selección de las imágenes incluidas en el texto.

${ }^{3}$ Uno de los primeros decretos promulgados tras la toma de San Cristóbal fue el que determinaba que todos los habitantes del estado debían portar una cinta colorada y otra verde que simbolizaban la religión y la fe respectivamente. Quienes no llevaran dicho distintivo serían considerados traidores.

${ }^{4}$ En Chiapas no llegó a aplicarse el decreto emitido por Juárez en 1863 que imponía la pena de confiscación de bienes pertenecientes a: Los funcionarios públicos de la intervención con sueldo o sin él. Los empleados de la misma en el orden civil, municipal o militar, y los agentes o comisionados en cualquiera de estos ramos. En general todos los que sirvan o auxilien directa o indirectamente a la causa de la intervención. (C. Berry, La reforma en Oaxaca. Una microbistoria de la revolución liberal, p 132).

${ }^{5}$ AMPAL/sc, 1866, exp. 1: Libro de actas.

${ }^{6}$ AMPAL/sC, 1867, exp. 1: Libro de actas.

${ }^{7}$ AMPAL/sC, 1867, exp.14: Comunicaciones de distintos particulares.

${ }^{8}$ AMPAL/sc, 1867, exp.1: Libro de actas.

${ }^{9}$ Ibidem.

${ }^{10}$ AMPAL/sC, 1872, exp.1: Libro de actas.

${ }^{11}$ Tomada del libro Apuntes históricos de San Cristóbal de Las Casas, Chiapas. p. 835, Hermilo López Sánchez, edición del autor, México, 1960, Archivo histórico de la ciudad de San Cristóbal.

${ }^{12}$ Lista de los munícipes del Ayuntamiento de 1863 que prestaron sus servicios al gobierno de Ortega: Porfirio Trejo, Ciríaco Aguilar, Patricio Trujillo, Vicente Guillén, Juan Cancino, B. Gabino, Pío Domínguez, Guadalupe Flores, Manuel Gutiérrez, José María Aguilar, Galo Cabrera, Tiburcio Ayanegui, A. López, Ambrosio Gutiérrez y Cristóbal Ruiz, AMPAL/sc, 1869, exp.3: Libro de borradores de correspondencia oficial.

${ }^{13}$ AMPAL/sc, 1864, exp.4: Comunicaciones del gobierno del Estado.

${ }^{14}$ AMPAL/sC, 1868, exp.22: Comunicaciones de la Jefatura Política.

${ }^{15}$ AMPAL/sc, 1869,: exp. 1: Libro de actas.

${ }^{16}$ La Brújula, 7 de octubre de 1870.

${ }^{17}$ AMPAL/sc, 1864, exp.28: De la Tesorería Municipal.

${ }^{18}$ AMPAL/sc, 1864, exp.28: De la Tesorería Municipal.

${ }^{19}$ Ibidem.

${ }^{20}$ AMPAL/sc, 1865, exp.25: Libro de actas.

${ }^{21}$ Ibidem.

${ }^{22} \mathrm{Al}$ hacer la convocatoria para participar en los remates en enero de 1865 se establecieron unas bases de licitación que para las tres garitas ascendía a \$145 mensuales. Después de la rebaja aplicada, las cantidades ingresadas quedaron reducidas a $\$ 110.91$. Durante los siguientes años los ingresos se mantuvieron casi inalterables.

${ }^{23}$ AMPAL/SC, 1864, exp.5: Comunicaciones de la Jefatura Política.

${ }^{24}$ AMPAL/sc, 1868, exp.2: Libro de minutas.

${ }^{25}$ Ibidem.

${ }^{26}$ Ibidem.

${ }^{27}$ Colección de la familia Moscoso Pohlenz, Archivo histórico de la ciudad de San Cristóbal.

${ }^{28}$ AMPAL/sc, 1864, exp.5: Comunicaciones de la Jefatura Política.

${ }^{29}$ El Espíritu del Siglo, 5 de febrero de 1874.

${ }^{30}$ AMPAL/sC, 1866, exp.1: Libro de actas.

${ }^{31}$ Ibidem.

32 AMPAL/sC, 1866, exp.15: Comunicaciones de la Jefatura Política.

${ }^{33}$ AMPAL/sc, 1867, exp.1: Libro de actas.

${ }^{34}$ AMPAL/sc, 1869, exp.1: Libro de actas.

35 AMPAL/sc, 1866, exp.1: Libro de actas.

${ }^{36}$ Ibidem.

${ }^{37}$ No he creído oportuno desarrollar más el tema de la llamada Guerra de Castas de 1869 en este trabajo por tratarse de una 
cuestión ya analizada en repetidas ocasiones por varios autores. Para tener una versión crítica y bien documentada de aquellos acontecimientos es fundamental la lectura del artículo de Jan Rus titulado “¿Guerra de castas según quién? Indios y ladinos en los sucesos de 1869", en Chiapas: Los rumbos de otra historia. Para conocer las versiones de los autores locales son importantes las obras de Vicente Pineda, Sublevaciones indígenas en Chiapas y de Prudencio Moscoso, Rebeliones indígenas en Los Altos de Chiapas. Lo que aquí pretendo es añadir a lo ya desarrollado por otros autores algunas informaciones del archivo municipal de San Cristóbal que permitan mejorar la comprensión de los antecedentes y la vivencia de los acontecimientos de 1869 en la capital de Los Altos.

${ }^{38}$ AMPAL/sC, 1868, exp.17: Una comunicación del gobierno del Estado.

${ }^{39}$ AMPAL/sC, 1868, exp. 2: Libro de actas.

${ }^{40}$ AMPAL/sc, 1869, exp.1: Libro de actas.

${ }^{41}$ AMPAL/sC, 1869, exp.9: 20 circulares de la presidencia municipal.

${ }^{42}$ Ignacio Fernández de Galindo es el personaje más inquietante y menos conocido de aquel drama. Para unos se trataba de un radical revolucionario que organizó militarmente a los chamulas; para otros, un espía del gobierno de Pantaleón Domínguez. En la documentación municipal se señala que Ignacio Fernández de Galindo había sido comisionado por el gobierno del estado en abril de 1869 para ...que forme la carta geográfica del estado.... AMPAL/sC, 1869, exp.1: Libro de actas.

El 26 de mayo, Fernández de Galindo salió de San Cristóbal acompañado de su esposa Luisa de Quevedo y su ayudante Benigno Trejo para unirse a los indígenas concentrados en Tzajalhemel.

${ }^{43}$ Colección de la familia Moscoso Pohlenz, reproducción del Archivo Histórico de la ciudad de San Cristóbal.

${ }^{44}$ AMPAL/sc, 1870, exp. 57: Comunicaciones diversas.

${ }^{45}$ La Brújula, 23 de julio de 1869. Los editores de La Brújula eran Joaquín Peña, Carlos Ballinas, Fernando Zepeda, Flavio Antonio Paniagua, José Leonardo Pineda y Feliciano José Lazos.

${ }^{46}$ AMPAL/sC, 1871, exp.11: Comunicaciones de Jefes de Cuartel.

${ }^{47}$ AMPAL/sc, 1872, exp.4: Comunicaciones de la Jefatura Política.

${ }^{48}$ Ibidem.

${ }^{49}$ Ibidem.

${ }^{50} \mathrm{El}$ alcaide era la persona encargada de mantener la custodia de los presos en las cárceles.
${ }^{51}$ Los carcelajes consistían en ciertas cantidades de dinero que ilegalmente pagaban los presos a los alcaides para salir de la prisión.

52 AMPAL/sC, 1872, exp.5: Comunicaciones de distintas personas.

53 AMPAL/sC, 1873, exp.7: Legajo de Comunicaciones de la Jefatura Política.

\section{Bibliografía}

Aubry, Andrés e Inda, 1989, Angélica (Eds.), El diario de Francisco Villafuerte, 1832-1879, Boletín del Archivo Histórico Diocesano IV, 1 y 2, San Cristóbal de Las Casas.

Benjamin, Thomas Louis, 1990, El camino a Leviatán. Chiapasy el Estado mexicano,1891-1947, Consejo Nacional para la Cultura y las Artes, México.

Corzo, Angel Albino,1990, Reseña de varios sucesos acaecidos en el estado de Chiapas durante la intervención francesa en la república, Gobierno del Estado de Chiapas, Tuxtla Gutiérrez.

Inda, Angélica (Ed.),1986, Dos siglos de Chamula, 1778-1985, Boletín del Archivo Histórico Diocesano III, 1 y 2, San Cristóbal de Las Casas.

Manguen, Juan y Montesinos, Irma, 1981, La guerra de castas de 1869, Universidad Autónoma de Chiapas, Tuxtla Gutiérrez.

Moscoso Pastrana, Prudencio, 1992, Rebeliones indígenas en los Altos de Chiapas, Universidad Autónoma de México, México. Paniagua, Flavio Antonio, 1888, Florinda, San Cristóbal de Las Casas.

—, 1990, Lágrimas del corazón, Instituto Chiapaneco de Cultura, Tuxtla Gutiérrez.

—, 1991, Una rosa y dos espinas, Instituto Chiapaneco de Cultura, Tuxtla Gutiérrez.

Pineda,Vicente, 1986, Sublevaciones indígenas en Chiapas. Gramática y diccionario tzeltal, Instituto Nacional Indigenista, México.

Rus, Jan, 1995, “¿Guerra de castas según quién? Indios y ladinos en los sucesos de 1869", en Chiapas: los rumbos de otra historia, UNAM/CIESAS/CEMCA, México.

Trens, Manuel B., 1956, El Imperio en Chiapas, 1863-1864, Gobierno del Estado de Chiapas, Tuxtla Gutiérrez.

—, 1957, Historia de Chiapas. Desde los tiempos más remotos hasta la caída del Segundo Imperio, edición del autor, México.

Viqueira, Juan Pedro y Ruz, Mario Humberto (eds.), 1995, Chiapas: Los rumbos de otra historia, UNAM/CIESAS/CEMCA, México. 